() 2018, THE AUTHORS. Published by FASS Inc. and Elsevier Inc. on behalf of the American Dairy Science Association ${ }^{\circledR}$.

This is an open access article under the CC BY-NC-ND license (http://creativecommons.org/licenses/by-nc-nd/3.0/).

\title{
Short communication: Methicillin-resistant Staphylococcus aureus in conventional and organic dairy herds in Germany
}

\author{
Bernd-Alois Tenhagen, ${ }^{* 1}$ Katja Alt, ${ }^{*}$ Beatrice Pfefferkorn, $†$ Lars Wiehle, $†$ Annemarie Käsbohrer, ${ }^{*}$ \\ and Alexandra Fetsch* \\ *Department of Biological Safety, German Federal Institute for Risk Assessment (BfR), 10589 Berlin, Germany \\ †Federal Office for Consumer Protection and Food Safety (BVL), 10117 Berlin, Germany
}

\section{ABSTRACT}

Methicillin-resistant Staphylococcus aureus (MRSA) have been described repeatedly in dairy herds. In this study, we compared the prevalence and antimicrobial resistance of MRSA in bulk tank milk from conventional and organic dairy herds in Germany. Samples were collected from 372 conventional and 303 organic dairy herds throughout Germany. Bulk tank milk (25 $\mathrm{mL}$ ) was tested for MRSA using an established double selective enrichment method. The MRSA isolates were typed using spa typing and tested for resistance to 19 antimicrobials using the broth microdilution method. Methicillin-resistant Staph. aureus was detected more frequently in bulk tank milk from conventional (9.7\%) than from organic $(1.7 \%)$ dairy herds. Herd size and region were associated with differences in prevalence. Most isolates (38/41) were from spa types associated with the livestock-associated clonal complex CC398. Isolates from conventional herds tended to be more resistant to antimicrobials; however, because of the limited number of isolates from organic herds, no statistical tests were performed. In conclusion, prevalence of MRSA in dairy herds in Germany seems to be increasing and is more prevalent in regions with high livestock density. Organic herds are also affected although at a lower level. Therefore, MRSA should be specifically included in biosecurity protocols for dairy herds, and effective control measures need to be investigated.

Key words: methicillin-resistant Staphylococcus aureus (MRSA), organic, conventional, bulk tank milk

\section{Short Communication}

Staphylococcus aureus is an important mastitis pathogen for dairy cows (Tenhagen et al., 2009). In recent years, methicillin-resistant Staph. aureus (MRSA) has

Received March 27, 2017

Accepted December 4, 2017.

${ }^{1}$ Corresponding author: Bernd-Alois.Tenhagen@bfr.bund.de been repeatedly described in dairy herds, with herdlevel prevalence up to $9.9 \%$ (Nemeghaire et al., 2014; Tenhagen et al., 2014; Parisi et al., 2016). Within-herd prevalence was up to 60\% (Spohr et al., 2011; Locatelli et al., 2017). About $10 \%$ of the dairy herds in Belgium with cases of dairy cow mastitis caused by Staph. aureus had a problem with MRSA (Vanderhaeghen et al., 2010).

In Germany, previous investigations estimated MRSA prevalence in bulk tank milk (BTM) from dairy herds to be 4.1 and $4.7 \%$ in 2009 and 2010, respectively (BVL, 2012; Tenhagen et al., 2014). However, in contrast to the current investigation, those studies did not differentiate between conventional and organic herds. Methicillin-resistant Staph. aureus has been shown to be associated with both clinical and subclinical mastitis (Fessler et al., 2010; Spohr et al., 2011; Silva et al., 2014). Moreover, people working on MRSA-positive dairy farms are at increased risk of carrying MRSA and could therefore introduce MRSA into the healthcare system when receiving medical treatment (Spohr et al., 2011; Antoci et al., 2013).

The risk of acquiring MRSA through the consumption of milk has been estimated to be low due to mandatory heat treatment of milk before marketing (Spohr et al., 2011). However, this estimation might differ for the consumption of raw milk and raw milk products, because this exposes consumers to viable bacteria. So far, no reports indicating the spread of livestock-associated MRSA to humans via milk have been published.

Resistant bacteria such as MRSA are fostered by the routine use of antimicrobials. European Council Regulation (EC) No. 834/2007 limits the number of antimicrobial treatments permitted in organic dairy cows. Therefore, organic farms in Germany and elsewhere in Europe are considered to use lesser amounts of antimicrobials than conventional farms, and organic herds might be less prone to harboring MRSA than conventional herds. This has already been shown for pigs, where MRSA prevalence was lower at both the herd and intraherd level in organic farms (Heine, 2011). 
Table 1. Prevalence of methicillin-resistant Staphylococcus aureus in bulk tank milk of conventional and organic dairy herds in Germany in 2014 by region and herd size

\begin{tabular}{|c|c|c|c|c|}
\hline \multirow[b]{2}{*}{ Variable } & \multicolumn{2}{|c|}{ Conventional } & \multicolumn{2}{|c|}{ Organic } \\
\hline & $\begin{array}{l}\text { Samples } \\
\text { assigned }^{1}\end{array}$ & $\begin{array}{c}\text { No./total } \\
(\%)\end{array}$ & $\begin{array}{c}\text { Samples } \\
\text { assigned }^{1}\end{array}$ & $\begin{array}{c}\text { No./total } \\
(\%)\end{array}$ \\
\hline \multicolumn{5}{|l|}{ Region } \\
\hline Northwest & 147 & $21 / 141(14.9)$ & 59 & $0 / 51(0)$ \\
\hline Southwest & 163 & $6 / 156(3.8)$ & 279 & $5 / 207(2.4)$ \\
\hline East & 74 & $9 / 75(11.9)$ & 46 & $0 / 45(0)$ \\
\hline \multicolumn{5}{|l|}{ Herd size $^{2}$} \\
\hline$<50$ & & $6 / 95(6.3)$ & & $3 / 114(2.6)$ \\
\hline $50-79$ & & $6 / 70(8.6)$ & & $2 / 99(2.0)$ \\
\hline 80-199 & & $9 / 96(8.6)$ & & $0 / 56(0)$ \\
\hline 200-499 & & $6 / 41(14.6)$ & & $0 / 9(0)$ \\
\hline$\geq 500$ & & $7 / 20(35.0)$ & & $0 / 0$ \\
\hline $\bar{T}$ otal & & $36 / 372(9.7)$ & & $5 / 303(1.7)$ \\
\hline
\end{tabular}

${ }^{1}$ Samples assigned according to the sampling plan

${ }^{2}$ Only 612 herds included because of missing data.

However, published data on dairy cattle comparing organic and conventional farming are limited to a US study that found only one MRSA in BTM from 288 tested herds (Cicconi-Hogan et al., 2014); therefore, potential differences could not be analyzed.

The purpose of this study was to estimate the herdlevel prevalence of MRSA in organic and conventional dairy herds in Germany. The study was part of a national monitoring program for zoonotic agents and resistant bacteria in the food chain carried out by the regional veterinary services in cooperation with national reference laboratories (Kaesbohrer et al., 2012; BVL, 2016).

Selection of herds was based on a national sampling plan designed to cover the different German federal states (Länder) according to their share of the national conventional and organic dairy cow population. On the national level, the number of herds to be sampled was calculated for each region based on the distribution of cows rather than herds to account for substantially different distributions of herd sizes in different regions in Germany (i.e., smaller herds in the south and large herds in the east). However, farm size was not considered when choosing herds within a state. Data on the distribution of dairy cows were provided by the national bureau of statistics (www.destatis.de). Minimum herd size was 20 lactating cows. Separate sampling plans were designed for the 2 categories of herds as the proportion of organic dairy herds is still low. Selection of the individual herds was the responsibility of the veterinary authorities of the Länder.

For data analysis, Germany was divided into 3 major regions: (1) the northwest, characterized by an overall high density of livestock of all species in medium-sized herds, included Schleswig-Holstein, Lower Saxony, and North Rhine-Westphalia; (2) the southwest, character- ized by heterogeneous animal densities and smaller herds (Rhineland-Palatinate, Hesse, Bavaria, BadenWürttemberg, Saarland); and (3) the east, characterized by an overall low animal density but large herds (Mecklenburg-Western Pomerania, Brandenburg, Saxony-Anhalt, Thuringia, Saxony). Regional distribution of cattle differed between conventional and organic cows, with relatively more organic cows in the southwest and fewer in the east and northwest, leading to differing sample numbers per region (Table 1 ).

To sample and detect MRSA, $25 \mathrm{~mL}$ of bulk tank milk was collected on farm, transported to the regional state laboratory at $4^{\circ} \mathrm{C}$, and examined using a harmonized double selective enrichment protocol, as described previously (Tenhagen et al., 2014), within $48 \mathrm{~h}$ of arrival at the laboratory. Presumptive MRSA (one randomly chosen isolate from the selective agar or sample) were submitted to the National Reference Laboratory (NRL; Berlin, Germany) for coagulase-positive staphylococci, including Staph. aureus, where isolates were confirmed as MRSA by an in-house multiplex PCR simultaneously targeting the 23S rDNA gene specific for Staphylococcus species (Straub et al., 1999), the nuclease gene nuc, which is specific for Staph. aureus, and the resistance gene mecA (Poulsen et al., 2003). Isolates of Staph. aureus that were resistant to cefoxitin but negative for $m e c A$ would have additionally been tested for mec $C$ but no isolate fulfilled these criteria. Furthermore, MRSA isolates were typed according to the repeat pattern of their spa gene (Shopsin et al., 1999). Assignment of spa types to multilocus sequence types (MLST) was done based on previously confirmed associations in the NRL. Multilocus sequence typing (Enright et al., 2000) was done on isolates that either could not be assigned to a spa type (1 isolate) or showed spa types not previously seen in the NRL. The antimicrobial susceptibility 
Table 2. Association of methicillin-resistant Staphylococcus aureus-positive samples with herd size, region, and farming type (conventional vs. organic) in 612 herds

\begin{tabular}{|c|c|c|c|c|c|c|c|c|}
\hline Variable & Category & $\begin{array}{l}\text { Coefficient of } \\
\text { regression }\end{array}$ & $\mathrm{SE}$ & df & $P$-value & $\begin{array}{l}\text { Odds } \\
\text { ratio }\end{array}$ & \multicolumn{2}{|c|}{$95 \%$ CI of odds ratio } \\
\hline Herd size & & 0.003 & 0.001 & 1 & 0.001 & 1.003 & 1.001 & 1.004 \\
\hline
\end{tabular}

of Staph. aureus was examined by broth microdilution according to the guidelines of Clinical and Laboratory Standards Institute (Wayne, PA) at the NRL for antimicrobial resistance and included 19 different antimicrobial substances. The full process of confirmation, further characterization, and antimicrobial resistance testing is described elsewhere (Kraushaar et al., 2017).

The association of a sample being positive for MRSA with type of farm (organic or conventional), region, and herd size was examined using the binary logistic regression procedure of IBM SPSS Statistics (version 21.0, IBM Corp., Armonk, NY) with test result as the binary outcome and production type (conventional/organic), region (3 categories), and herd size as independent variables.

Because conventional and organic herds were not evenly distributed between the 3 regions, separate regressions for the 2 production types including herd size or region only were additionally carried out on the effect of herd size and region.

In total, 675 herds (372 conventional and 303 organic) from all regions were tested for MRSA in Germany in 2014 (Table 1). The prevalence of MRSA was higher in BTM samples from conventional dairy herds $(9.7 \%)$ compared with samples from organic herds $(1.7 \%, P$ $<0.01)$. Herd size varied between regions and production type. Herd size (median, range) was highest in the east $(180,20-1,650)$, followed by the northwest $(72.5$, 9-851) and the southwest (52, 7-512). Conventional herds were larger than organic herds $(80,8-1,650$ vs. 54, 7-320).

Logistic regression analysis was carried out on a subset of the tested herds because information on herd size was not available for 63 herds, leaving 612 (331 conventional and 281 organic) herds for this analysis. Overall, samples were more likely to be positive in the northwest than in the southwest (Table 2). This applied especially to conventional herds (odds ratio 4.6, 95\% CI: 1.7-12.7). In contrast, all 5 MRSA-positive organic herds were in the southwest. Prevalence in the east did not differ significantly from that in the other 2 regions. Although overall and in conventional herds, the probability of a sample being positive increased with herd size, this could not be shown for organic herds. In fact, all 65 organic herds with $>80$ lactating cows were negative, whereas of the 166 conventional herds with $>80$ cows, 22 were positive (13.3\%). Of the conventional herds with $<80$ lactating cows, $7.3 \%$ were positive; the proportion was $2.3 \%$ in organic herds of this size.

Overall, 41 different MRSA isolates (36 from conventional, 5 from organic herds) were submitted to the NRL for further typing and susceptibility testing. All submitted isolates were confirmed as MRSA. Most isolates (38/41) were assigned to the most frequent livestock-associated MRSA clonal complex, CC398. The spa types t011 and t034 were most frequent (19 and 10 isolates from conventional herds and 2 each from organic herds); all other spa types were observed only once (t108, t127, t1430, t2346, t2576, and t4677 in conventional herds, t790 in an organic herd). Three isolates were each from different CC: one isolate from CC1 (t127), one isolate from CC9 (t1430), both from conventional herds, and one isolate from CC22 (t790) from an organic herd. The latter was confirmed by MLST. One isolate could not be spa typed. However, MLST revealed that it was sequence type ST398.

Antimicrobial resistance tended to be more pronounced in isolates from conventional herds, as indicated by the number of antimicrobials to which the isolates were resistant. The proportion of resistant isolates was numerically higher for conventional herds for 12 antimicrobials, equally 100 or $0 \%$ for 4 antimicrobials, and lower for 3 substances (Table 3). Because of the low number of isolates from organic herds, significance testing was not performed.

All isolates were resistant to cefoxitin and penicillin; most (39/41) were also resistant to tetracycline. Isolates susceptible to tetracycline were from spa types not as- 
sociated with CC398 (t1430 and t790). Several isolates from conventional $(8 / 36)$ and organic $(2 / 5)$ herds were resistant to ciprofloxacin and most were from spa types t011 and t034. One isolate from a conventional herd was resistant to linezolid and rifampicin. No isolates were resistant to vancomycin or mupirocin.

The prevalence of MRSA in BTM was higher than in similar previous studies in dairy cattle in Germany (Friedrich et al., 2011; Kreausukon et al., 2012; Tenhagen et al., 2014). Because the distribution of samples across the country was based on the regional number of cows rather than herds, larger herds were more likely to be tested, which may have biased upward the prevalence estimate. National monitoring is designed to represent the production sector, which is more accurately represented by the number of cows than the number of herds. Tenhagen et al. (2014) used the same sampling design as the current study except that they did not sample organic farms separately. However, most of the farms included in 2009 and 2010 would have been conventional, because organic farms had a very limited share (1.9\% in 1999) among German dairy farms at that time (Blumöhr, 2002). Combining the data of 2009 and 2010 , the increase in the proportion of positive samples was significant (4.4 to $9.7 \%, \chi^{2}=10.9$ ); the reason for this increase is not clear. Staphylococcus aureus tends to persist in dairy herds in the absence of specific control programs; hence, herds that are positive at one time are not likely to become negative at a further sampling (Barkema et al., 2006). Moreover, strategies to control mastitis caused by Staph. aureus in dairy herds include the indiscriminant application of $\beta$-lactam antibiotics to cows as blanket dry-cow therapy. Because MRSA are, by definition, resistant to $\beta$-lactam antibiotics, this treatment may serve to select for $\beta$-lactam- and cephalosporin-resistant bacteria.

A recent publication from Italy indicated that regional pig density may be associated with an increased risk for dairy farms to be MRSA positive (Locatelli et al., 2016). Potential spillover from pig farms has been suspected previously (Friedrich et al., 2011). Although this might be a relevant factor in northwest Germany, where very high livestock densities are reported and the highest prevalence determined, the density of pig farms is limited in eastern Germany. However, herds in eastern Germany tend to be larger and have been reported to have high replacement rates (Kreausukon, 2011), indicating that MRSA could have been introduced by trade of colonized animals, a route that has been demonstrated for pigs (Broens et al., 2011; EspinosaGongora et al., 2012).

The lower detection rates of MRSA in BTM from organic herds observed in the present study were expected. Several factors may have contributed to this difference for different production systems. First, organic herds tend to be smaller than conventional herds, which may have reduced their risk. However, all MRSApositive organic herds had fewer than 80 lactating cows, whereas larger organic herds were negative. Second, animal trade between the 2 systems is limited by the

Table 3. Antimicrobial resistance (number and \% of resistant isolates) of methicillin-resistant Staphylococcus aureus from bulk tank milk samples from dairy herds in Germany in 2014

\begin{tabular}{|c|c|c|c|c|c|c|c|}
\hline \multirow[b]{2}{*}{ Antimicrobial } & \multicolumn{2}{|c|}{$\begin{array}{l}\text { Conventional } \\
\quad(\mathrm{n}=36)\end{array}$} & \multicolumn{2}{|c|}{$\begin{array}{l}\text { Organic } \\
(\mathrm{n}=5)\end{array}$} & \multicolumn{2}{|c|}{ Total $(\mathrm{n}=41)$} & \multirow{2}{*}{$\begin{array}{c}\text { Cut-off } \\
\text { value }^{1}(\mathrm{mg} / \mathrm{L})\end{array}$} \\
\hline & No. & $\%$ & No. & $\%$ & No. & $\%$ & \\
\hline Gentamicin & 4 & 11.1 & 3 & 60 & 7 & 17.1 & $\leq 2$ \\
\hline Kanamycin & 8 & 22.2 & 3 & 60 & 11 & 26.8 & $\leq 8$ \\
\hline Streptomycin & 12 & 33.3 & 1 & 20 & 13 & 31.7 & $\leq 16$ \\
\hline Chloramphenicol & 3 & 8.3 & 0 & 0 & 3 & 7.3 & $\leq 16$ \\
\hline Cefoxitin & 36 & 100 & 5 & 100 & 41 & 100.0 & $\leq 4$ \\
\hline Ciprofloxacin & 8 & 22.2 & 2 & 40 & 10 & 24.4 & $\leq 1$ \\
\hline Penicillin & 36 & 100 & 5 & 100 & 41 & 100.0 & $\leq 0.12$ \\
\hline Sulfamethoxazole & 1 & 2.8 & 0 & 0 & 1 & 2.4 & $\leq \overline{12} 8$ \\
\hline Trimethoprim & 16 & 44.4 & 2 & 40 & 18 & 43.9 & $\leq 2$ \\
\hline Tetracycline & 35 & 97.2 & 4 & 80 & 39 & 95.1 & $\leq 1$ \\
\hline Clindamycin & 17 & 47.2 & 1 & 20 & 18 & 43.9 & $\leq 0.25$ \\
\hline Erythromycin & 16 & 44.4 & 1 & 20 & 17 & 41.5 & $\leq 1$ \\
\hline Mupirocin & 0 & 0 & 0 & 0 & 0 & 0.0 & $\leq 1$ \\
\hline Rifampicin & 1 & 2.8 & 0 & 0 & 1 & 2.4 & $\leq 0.03$ \\
\hline Linezolid & 1 & 2.8 & 0 & 0 & 1 & 2.4 & $\leq 4$ \\
\hline Fusidic acid & 2 & 5.6 & 0 & 0 & 2 & 4.9 & $\leq 0.5$ \\
\hline Quinupristin/dalfopristin & 14 & 38.9 & 1 & 20 & 15 & 36.6 & $\leq 1$ \\
\hline Tiamulin & 14 & 38.9 & 1 & 20 & 15 & 36.6 & $\leq 2$ \\
\hline Vancomycin & 0 & 0 & 0 & 0 & 0 & 0.0 & $\leq 2$ \\
\hline
\end{tabular}

${ }^{1}$ Epidemiological cut-off values as provided by EUCAST (www.eucast.org; accessed July 16, 2017). 
restrictions imposed by European Council Regulation (EC) No. 834/2007, which limit the trade of potential adult carrier animals between conventional and organic herds. Lower detection rates in organic herds are also in line with a report on pigs from Germany that found less MRSA in organic pig farms than in conventional farms (Heine, 2011). Finally, organic farms are expected to use less antimicrobials (Vaarst and Bennedsgaard, 2001; Zwald et al., 2004). However, comparative data on the extent of antimicrobial use in organic and conventional dairy herds are not available for Germany.

Regional distribution of MRSA-positive herds differed between organic and conventional herds. If spillover between farms is relevant, we can assume that organic farms are similarly exposed as conventional farms within the same region, and positive farms should therefore have a similar regional distribution. This was not the case in our study. In contrast, all positive organic herds were in the southwest, whereas most positive conventional herds were in the northwest. Further investigations on the effect and interaction of risk factors, including trade, spillover from other farms, and antimicrobial use, need to be carried out to fully understand the spread within and between populations.

Most isolates displayed spa types assigned to CC398. This is in line with previous reports on MRSA in dairy cattle in Germany that solely described CC398associated spa types (Fessler et al., 2010; Kreausukon et al., 2012; Tenhagen et al., 2014). Assignment of isolates to clonal complexes based on spa typing may occasionally lead to misclassification because spa types may sometimes occur in association with different clonal complexes. However, in our experience, this is a comparatively rare event with isolates from livestock; therefore, we only used MLST in selected cases. The presence of CC1 MRSA in dairy herds has previously been described mainly in Italy (Benedetti et al., 2010; Pilla et al., 2012; Cortimiglia et al., 2016). Isolates assigned to CC9 are widespread in poultry food chains in Germany (Richter et al., 2012; Vossenkuhl et al., 2014). The spa type t790 (sequence type ST22) has not previously been described in dairy herds but is prevalent in human isolates in Germany and other European countries, indicating potential spillover from humans to cattle or human contamination of the BTM. However, no further data on the farm are available to clarify these findings. So far, in cattle in Germany, nonCC398 strains have only been identified in veal calves at slaughter (Tenhagen et al., 2014).

Resistance to tetracycline among most isolates is in line with previous findings of MRSA in cattle (Fessler et al., 2012; Nemeghaire et al., 2014; Tenhagen et al., 2014). Interestingly, both isolates that were susceptible to tetracycline were non-CC398 strains, in agreement with previous studies that highlighted differences between spa types with respect to antimicrobial resistance (Tenhagen et al., 2014; Vossenkuhl et al., 2014). In the current study, however, the proportion of isolates resistant to ciprofloxacin among CC398-associated spa types was higher than previously described (Bardiau et al., 2013; Nemeghaire et al., 2014; Tenhagen et al., 2014). The reason for this development is not clear. In a similar survey in dairy herds carried out in 2009 and 2010 in Germany, no isolates resistant to ciprofloxacin were observed (Tenhagen et al., 2014). In Germany, fluoroquinolones are licensed for use - and are used - in dairy cattle and calves (Kreausukon et al., 2012; Merle et al., 2012); however, published data on the development of the use of these drugs are limited. In contrast to that of most other antimicrobial groups, sales of fluoroquinolones in Germany have increased from 2011 to 2014 (ESVAC, 2016). However, these data do not specify the proportions of the drugs used for different animal species (ESVAC, 2013, 2016).

In conclusion, MRSA were present in BTM samples from organic dairy herds less often than in conventional dairy herds in Germany in 2014. In addition to production system, the presence of MRSA was associated with larger farms and region. The prevalence of MRSA in BTM from conventional dairy herds in Germany has increased over time since 2009-2010. In contrast to previous reports, non-CC398 MRSA isolates were observed in both types of herds. Close monitoring of this development is warranted, and further research is needed to analyze the drivers of this increase and the genetic characteristics of MRSA in dairy cattle. Meanwhile, farmers should include MRSA in their biosecurity protocols.

\section{ACKNOWLEDGMENTS}

The authors gratefully acknowledge the excellent work - the basis for the successful monitoring programs - of the regional veterinary officials and regional laboratories. Part of this work was carried out in the framework of the project MedVet-Staph funded by the German Federal Ministry of Education and Science (BMBF; research grant: 01KI1014C; Berlin, Germany). This study was furthermore supported by the German Federal Institute for Risk Assessment (internal BfRgrant 44-001). The authors thank Katja Drache, Daniel Leeser, and Ylanna Kelner Burgos (BfR, Berlin, Germany) for excellent technical assistance.

\section{REFERENCES}

Antoci, E., M. R. Pinzone, G. Nunnari, S. Stefani, and B. Cacopardo. 2013. Prevalence and molecular characteristics of methicillin-resis- 
tant Staphylococcus aureus (MRSA) among subjects working on bovine dairy farms. Infez. Med. 21:125-129.

Bardiau, M., K. Yamazaki, J. N. Duprez, B. Taminiau, J. G. Mainil, and I. Ote. 2013. Genotypic and phenotypic characterization of methicillin-resistant Staphylococcus aureus (MRSA) isolated from milk of bovine mastitis. Lett. Appl. Microbiol. 57:181-186. https:// doi.org/10.1111/lam.12099.

Barkema, H. W., Y. H. Schukken, and R. N. Zadoks. 2006. Invited review: The role of cow, pathogen, and treatment regimen in the therapeutic success of bovine Staphylococcus aureus mastitis. J. Dairy Sci. 89:1877-1895. https://doi.org/10.3168/jds.S0022 -0302(06)72256-1.

Benedetti, V., P. Cremonesi, S. Ferrari, B. Castiglioni, M. Fabbi, N. Vicari, C. Garbarino, A. Battisti, A. Franco, F. Feltrin, and M. Luini. 2010. Staphylococcus aureus meticillino-resistenti (MRSA) da camioni di latte bovino. Large Anim. Rev. 16:67-70.

Blumöhr, T. 2002. Ökologischer Landbau 2001 Ergebnisse und Weiterentwicklung der statistischen. Erfassung. Wirtsch. Stat. 2:471480.

Broens, E. M., E. A. Graat, P. J. van der Wolf, A. W. van de Giessen, D. E. Van, J. A. Wagenaar, N. A. Van, D. J. Mevius, and M. C. De Jong. 2011. MRSA CC398 in the pig production chain. Prev. Vet. Med. 98:182-189.

BVL. 2012. Berichte zur Lebensmittelsicherheit 2010: Zoonosen-Monitoring. Bundesamt für Verbraucherschutz und Lebensmittelsicherheit, Berlin, Germany.

BVL. 2016. Berichte zur Lebensmittelsicherheit 2014: Zoonosen-Monitoring. Bundesamt für Verbraucherschutz und Lebensmittelsicherheit, Berlin, Germany.

Cicconi-Hogan, K. M., N. Belomestnykh, M. Gamroth, P. L. Ruegg, L. Tikofsky, and Y. H. Schukken. 2014. Short communication: Prevalence of methicillin resistance in coagulase-negative staphylococci and Staphylococcus aureus isolated from bulk milk on organic and conventional dairy farms in the United States. J. Dairy Sci. 97:2959-2964. https://doi.org/10.3168/jds.2013-7523.

Cortimiglia, C., M. Luini, V. Bianchini, L. Marzagalli, F. Vezzoli, D. Avisani, M. Bertoletti, A. Ianzano, A. Franco, and A. Battisti. 2016. Prevalence of Staphylococcus aureus and of methicillin-resistant $S$. aureus clonal complexes in bulk tank milk from dairy cattle herds in Lombardy Region (Northern Italy). Epidemiol. Infect. 144:3046-3051. https://doi.org/10.1017/S0950268816001576.

Enright, M. C., N. P. Day, C. E. Davies, S. J. Peacock, and B. G. Spratt. 2000. Multilocus sequence typing for characterization of methicillin-resistant and methicillin-susceptible clones of Staphylococcus aureus. J. Clin. Microbiol. 38:1008-1015.

Espinosa-Gongora, C., E. M. Broens, A. Moodley, J. P. Nielsen, and L. Guardabassi. 2012. Transmission of MRSA CC398 strains between pig farms related by trade of animals. Vet. Rec. 170:564. https:// doi.org/10.1136/vr.100704.

ESVAC. 2013. Sales of veterinary antimicrobial agents in 25 EU/EEA countries in 2011. Third ESVAC report. European Surveillance of Veterinary Antimicrobial Consumption/European Medicines Agency, London, UK.

ESVAC. 2016. Sales of veterinary antimicrobial agents in 25 EU/EEA countries in 2014. Sixth ESVAC report. European Surveillance of Veterinary Antimicrobial Consumption/European Medicines Agency, London, UK.

Fessler, A., C. Scott, K. Kadlec, R. Ehricht, S. Monecke, and S. Schwarz. 2010. Characterization of methicillin-resistant Staphylococcus aureus ST398 from cases of bovine mastitis. J. Antimicrob. Chemother. 65:619-625. https://doi.org/10.1093/jac/dkq021.

Fessler, A. T., R. G. M. Olde Riekerink, A. Rothkamp, K. Kadlec, O. C. Sampimon, T. J. G. M. Lam, and S. Schwarz. 2012. Characterization of methicillin-resistant Staphylococcus aureus CC398 obtained from humans and animals on dairy farms. Vet. Microbiol. 160:77-84. https://doi.org/10.1016/j.vetmic.2012.05.005.

Friedrich, A., J. Rau, S. Hörlacher, and M. Spohr. 2011. Prevalence of methicillin-resistant Staphylococcus aureus (MRSA) in milk from dairy farms in Northern Wurttemberg. Tierarztl. Umsch. 66:195200
Heine, U. 2011. Epidemiologische Studie zum Vorkommen von MRSA (methicillin-resistente Staphylococcus aureus) in ökologisch wirtschaftenden Schweinebeständen, DVM Thesis. Stiftung Tierärztliche Hochschule, Hanover, Germany.

Kaesbohrer, A., A. Schroeter, B. A. Tenhagen, K. Alt, B. Guerra, and B. Appel. 2012. Emerging antimicrobial resistance in commensal Escherichia coli with public health relevance. Zoonoses Public Health 59(Suppl. 2):158-165.

Kraushaar, B., B. Ballhausen, D. Leeser, B.-A. Tenhagen, A. Käsbohrer, and A. Fetsch. 2017. Antimicrobial resistances and virulence markers in methicillin-resistant Staphylococcus aureus from broiler and turkey: A molecular view from farm to fork. Vet. Microbiol. https://doi.org/10.1016/j.vetmic.2016.05.022.

Kreausukon, K. 2011. Usage of antimicrobials on 60 dairy farms in Northern Germany and characterization of methicillin-resistant Staphylococcus aureus (MRSA) and extended spectrum betalactamases producing Escherichia coli (ESBLs-producing E. coli) isolated from bulk tank mil. Freie Universität Berlin, Fachbereich Veterinärmedizin, Berlin, Germany.

Kreausukon, K., A. Fetsch, B. Kraushaar, K. Alt, K. Muller, V. Kromker, K. H. Zessin, A. Kasbohrer, and B. A. Tenhagen. 2012. Prevalence, antimicrobial resistance, and molecular characterization of methicillin-resistant Staphylococcus aureus from bulk tank milk of dairy herds. J. Dairy Sci. 95:4382-4388.

Locatelli, C., P. Cremonesi, L. Bertocchi, M. G. Zanoni, A. Barberio, I. Drigo, G. Varisco, B. Castiglioni, V. Bronzo, and P. Moroni. 2016. Short communication: Methicillin-resistant Staphylococcus aureus in bulk tank milk of dairy cows and effect of swine population density. J. Dairy Sci. 99:2151-2156. https://doi.org/10.3168/jds .2015-9940.

Locatelli, C., P. Cremonesi, A. Caprioli, V. Carfora, A. Ianzano, A. Barberio, S. Morandi, A. Casula, B. Castiglioni, V. Bronzo, and P. Moroni. 2017. Occurrence of methicillin-resistant Staphylococcus aureus in dairy cattle herds, related swine farms, and humans in contact with herds. J. Dairy Sci. 100:608-619. https://doi.org/10 .3168/jds.2016-11797.

Merle, R., P. Hajek, A. Käsbohrer, C. Hegger-Gravenhorst, Y. Mollenhauer, M. Robanus, F. R. Ungemach, and L. Kreienbrock. 2012. Monitoring of antibiotic consumption in livestock: A German feasibility study. Prev. Vet. Med. 104:34-43. https://doi.org/10.1016/ j.prevetmed.2011.10.013.

Nemeghaire, S., M. A. Argudín, F. Haesebrouck, and P. Butaye. 2014 Epidemiology and molecular characterization of methicillin-resistant Staphylococcus aureus nasal carriage isolates from bovines. BMC Vet. Res. 10:153. https://doi.org/10.1186/1746-6148-10-153.

Parisi, A., M. Caruso, G. Normanno, L. Latorre, R. Sottili, A. Miccolupo, R. Fraccalvieri, and G. Santagada. 2016. Prevalence, antimicrobial susceptibility and molecular typing of methicillin-resistant Staphylococcus aureus (MRSA) in bulk tank milk from southern Italy. Food Microbiol. 58:36-42. https://doi.org/10.1016/j.fm.2016 .03 .004 .

Pilla, R., V. Castiglioni, M. E. Gelain, E. Scanziani, V. Lorenzi, M. Anjum, and R. Piccinini. 2012. Long-term study of MRSA ST1, t127 mastitis in a dairy cow. Vet. Rec. 170:312. https://doi.org/ 10.1136/vr.100510.

Poulsen, A. B., R. Skov, and L. V. Pallesen. 2003. Detection of methicillin resistance in coagulase-negative staphylococci and in staphylococci directly from simulated blood cultures using the EVIGENE MRSA Detection Kit. J. Antimicrob. Chemother. 51:419-421.

Richter, A., R. Sting, C. Popp, J. Rau, B. A. Tenhagen, B. Guerra, H. M. Hafez, and A. Fetsch. 2012. Prevalence of types of methicillinresistant Staphylococcus aureus in turkey flocks and personnel attending the animals. Epidemiol. Infect. 140:2223-2232. https://doi .org/10.1017/S095026881200009X.

Shopsin, B., M. Gomez, S. O. Montgomery, D. H. Smith, M. Waddington, D. E. Dodge, D. A. Bost, M. Riehman, S. Naidich, and B. N. Kreiswirth. 1999. Evaluation of protein A gene polymorphic region DNA sequencing for typing of Staphylococcus aureus strains. J. Clin. Microbiol. 37:3556-3563. 
Silva, N. C. C., F. F. Guimaraes, M. P. Manzi, A. F. Junior, E. Gomez-Sanz, P. Gomez, H. Langoni, V. L. M. Rall, and C. Torres. 2014. Methicillin-resistant Staphylococcus aureus of lineage ST398 as cause of mastitis in cows. Lett. Appl. Microbiol. 59:665-669. https://doi.org/10.1111/lam.12329.

Spohr, M., J. Rau, A. Friedrich, G. Klittich, A. Fetsch, B. Guerra, J. A. Hammerl, and B. A. Tenhagen. 2011. Methicillin-resistant Staphylococcus aureus (MRSA) in three dairy herds in southwest Germany. Zoonoses Public Health 58:252-261. https://doi.org/10 $.1111 /$ j.1863-2378.2010.01344.x.

Straub, J. A., C. Hertel, and W. P. Hammes. 1999. A 23S rDNAtargeted polymerase chain reaction-based system for detection of Staphylococcus aureus in meat starter cultures and dairy products. J. Food Prot. 62:1150-1156.

Tenhagen, B.-A., I. Hansen, A. Reinecke, and W. Heuwieser. 2009 Prevalence of pathogens in milk samples of dairy cows with clinical mastitis and in heifers at first parturition. J. Dairy Res. 76:179187. https://doi.org/10.1017/S0022029908003786.

Tenhagen, B. A., B. Vossenkuhl, A. Käsbohrer, K. Alt, B. Kraushaar, B. Guerra, A. Schroeter, and A. Fetsch. 2014. Methicillin-resistant
Staphylococcus aureus in cattle food chains-Prevalence, diversity, and antimicrobial resistance in Germany. J. Anim. Sci. 92:27412751. https://doi.org/10.2527/jas.2014-7665.

Vaarst, M., and T. W. Bennedsgaard. 2001. Reduced medication in organic farming with emphasis on organic dairy production. Acta Vet. Scand. Suppl. 95:51-57.

Vanderhagen, W., T. Cerpentier, C. Adriaensen, J. Vicca, K. Hermans, and P. Butaye. 2010. Methicillin-resistant Staphylococcus aureus (MRSA) ST398 associated with clinical and subclinical mastitis in Belgian cows. Vet. Microbiol. 144:166-171.

Vossenkuhl, B., J. Brandt, A. Fetsch, A. Käsbohrer, B. Kraushaar, K. Alt, and B. A. Tenhagen. 2014. Comparison of spa types, SCCmec types and antimicrobial resistance profiles of MRSA isolated from Turkeys at farm, slaughter and from retail meat indicates transmission along the production chain. PLoS One 9: https://doi.org/ 10.1371/journal.pone.0096308.

Zwald, A. G., P. L. Ruegg, J. B. Kaneene, L. D. Warnick, S. J. Wells, C. Fossler, and L. W. Halbert. 2004. Management practices and reported antimicrobial usage on conventional and organic dairy farms. J. Dairy Sci. 87:191-201. 